\title{
An Approach to Processing of Lithium-Ion Batteries for the Zero-Waste Recovery of Materials
}

\author{
D. $\operatorname{Marinos}^{1}$ - B. Mishra ${ }^{1}$
}

Published online: 28 July 2015

(C) The Minerals, Metals \& Materials Society (TMS) 2015

\begin{abstract}
A low-temperature, low-energy method for recovering all the valuable, economically viable, components from the spent lithium-ion batteries has been developed which has allowed the determination of pathways for complete recycling of the battery. Lithium present in the electrolyte has been selectively leached from lithium-ion batteries. Leaching conditions were optimized including time, temperature, solid/liquid ratio, and stirring velocity. All the samples were analyzed using ICP-MS for chemical composition. Leaching is conducted in a flotation machine that was able to separate plastics by flotation, creating bubbles without the use of any external chemical excess reagents. The pregnant solution was concentrated with lithium to a higher amount in order for it to be precipitated, and it was shown that the solution could be concentrated by recirculation of the leach solution. The next set of experiments were composed of battery shredding, steel separation by magnets, leaching with distilled water, and sizing using wet sieving to account for all the components of the battery. Every fraction is sent to rare-earth rolls separation and eddy current separation for full recovery.
\end{abstract}

Keywords Lithium - Recycling · Hydrometallurgy · Battery

The contributing editor for this article was S. Kitamura.

B. Mishra

bmishra@mines.edu

1 Metallurgical \& Materials Engineering, Colorado School of Mines, 1500 Illinois Street, Golden, CO 80401, USA

\section{Introduction}

Lithium-ion batteries are the most commonly used batteries. They have found use in a wide variety of applications from electronics to automotive over the past 25 years, and their volume is expected to rise more due to their use in automotive batteries [1, 2]. Lithium-ion batteries cannot be disposed into landfill due to safety, environmental reasons, and cost. Thus, recycling is needed not only to help the environment and reduce pollution but also as a source of valuable materials. A research performed by Begum Yazicioglu and Dr. Jan Tytgat proved that it is more energy efficient to recycle the used batteries than to get nickel and cobalt from primary resources. They also showed that recycling of the batteries produces less $\mathrm{CO}_{2}$ emissions than mining [3]. Although recycling is beneficial, it is still worthwhile to find the best recycling route to keep energy costs as low as possible.

Thus, over the last years, there has been a lot of effort invested to find ways to recycle lithium-ion batteries. Lots of valuable materials like cobalt, lithium, aluminum, copper, nickel, and manganese are present in a lithium-ion battery making it's recycling favorable. Many attempts have been researched and some of them are already used by the industry.

Although a lot of recycling processes for lithium-ion batteries are currently used industrially, they have some drawbacks (1) not all of them are lithium-ion battery dedicated processes [4] (2) in most of the processes, not all of the materials are recycled (3) usually the electrolyte, plastics, and organics are evaporated or are burned by pyrometallurgy and thus are not recovered [4] (4) hydrometallurgical processes can sometimes be questionable, from an economical point of view because of the low solid to liquid ratio [4] and the cost and handling of the 
reagents (especially if they are not recovered) (5) some battery components can not be leached easily. An example is the strong bond between oxygen and cobalt, which makes leaching with commonly, used reagents harder [4]. So, efforts have been focused on recovering $\mathrm{LiCoO}_{2}$ directly.

An efficient recycling process should follow the following requirements (1) Lithium-ion batteries can be composed of different materials, which are constantly being substituted by new ones thus making it harder to find a process that would treat all the different compositions at the same time [4] (2) the electrolyte $\left(\mathrm{LiPF}_{6}\right)$ should be recovered though it is very hard to recover because of its high reactivity with water, moisture, and heating [5] (3) the products produced from recycling have to be pure enough to meet the market needs and be competitive with new products. The main goals are to recover most of the products and be environmentally friendly.

This experimental work is focused on finding a lowtemperature, low-energy method of recovering lithium from the electrolyte and to develop pathways for complete recycling of the battery.

\section{Experimental}

\section{Methodology}

This research was aimed at finding a way to recycle the electrolyte without breaking the $\mathrm{LiPF}_{6}$ compound. It was found out, both from references $[4,6,7]$ and the experiments, that this was not possible due to partial decomposition of the electrolyte during shredding.

Because of the difficulty in recovering the electrolyte, the research focused in finding new recycling routes for spent lithium-ion batteries that would be able to recover most of the components and thus make the whole process more economically viable. The goal was to provide streams that would be of a smaller volume and of higher value compared with the starting material.

\section{Process Description}

A proposed flowsheet, shown in Fig. 1, has been developed. The material was first shredded to liberate the constituents of the lithium-ion battery and then passed through a low-intensity magnetic separator to remove all the ferromagnetic materials, which is primarily the steel battery shell.

The remaining material is leached at room temperature for $1 \mathrm{~h}$ using distilled water. Lithium is present usually as $\mathrm{LiCoO}_{2}$ in the cathode and in the electrolyte as $\mathrm{LiPF}_{6}$.
$\mathrm{LiCoO}_{2}$ is insoluble in water. After leaching, which could also be performed in a flotation cell, the air valve is opened, forming bubbles and helping the low specific gravity plastic and some fine particles stuck on the plastic, to float. The overflow is then sized, using wet sieving, into coarse and fine fractions to wash the plastics and separate fine particles. Plastics, at this stage, can be recycled, and the fine material is collected for further separation.

The remaining pulp, pregnant solution, and solids of high specific gravity go through multiple sieves to get different size fractions. Sieving again needs to be wet in order to clean the particles from the fine carbon and cathode powder. The very fine fraction is combined with the rest of the fines and it goes through the hydrocyclone and/or leached to recover carbon and cathode materials. Carbon is recovered from fines using pine oil to float it selectively.

The pulp that passes through the smallest sieve gets filtered, and the pregnant solution is recovered. Lithium concentration in solution is low, and in order to precipitate lithium carbonate from the solution, the concentration needs to be at least $1.4 \mathrm{~g} / \mathrm{L}$ at $100{ }^{\circ} \mathrm{C}$ and $2.4 \mathrm{~g} / \mathrm{L}$ at room temperature. Thus, at lower concentrations, the solution is recycled back into the leaching step. Once the concentration of the solution is built to higher levels, lithium carbonate is recovered using carbon dioxide or hydrochloric acid, to form $\mathrm{LiOH}$ to $\mathrm{LiCl}$, and sodium carbonate. This process is used industrially for the recovery of lithium.

The rest of the fractions that are obtained by sieving are sent separately for high-intensity magnetic separation followed by eddy-current separation. Theoretically, if all the particles are liberated and the sizes of the particles are close to each other, as in this case, the remaining products are separately recovered, e.g., copper, any remaining carbon or plastic, aluminum, etc.

In this work, shredding was performed and the magnetic separation and leaching conditions using distilled water were fully optimized. A flotation machine was used to remove the plastic. Sieving was performed with material balance and chemical components determination. Feasibility experiments were conducted to confirm the high magnetic intensity and eddy-current separation steps.

\section{Experimental Procedure}

\section{Battery Preparation}

The spent batteries were discharged. Shredding was done in a Fellner \& Ziegler shredder using a $2.2 \mathrm{~kW}$ Bauknecht motor. The shredder was fed from the top and has a sieve of 100-mm hole-size. Material balance was maintained at each step, starting with a spent battery. 


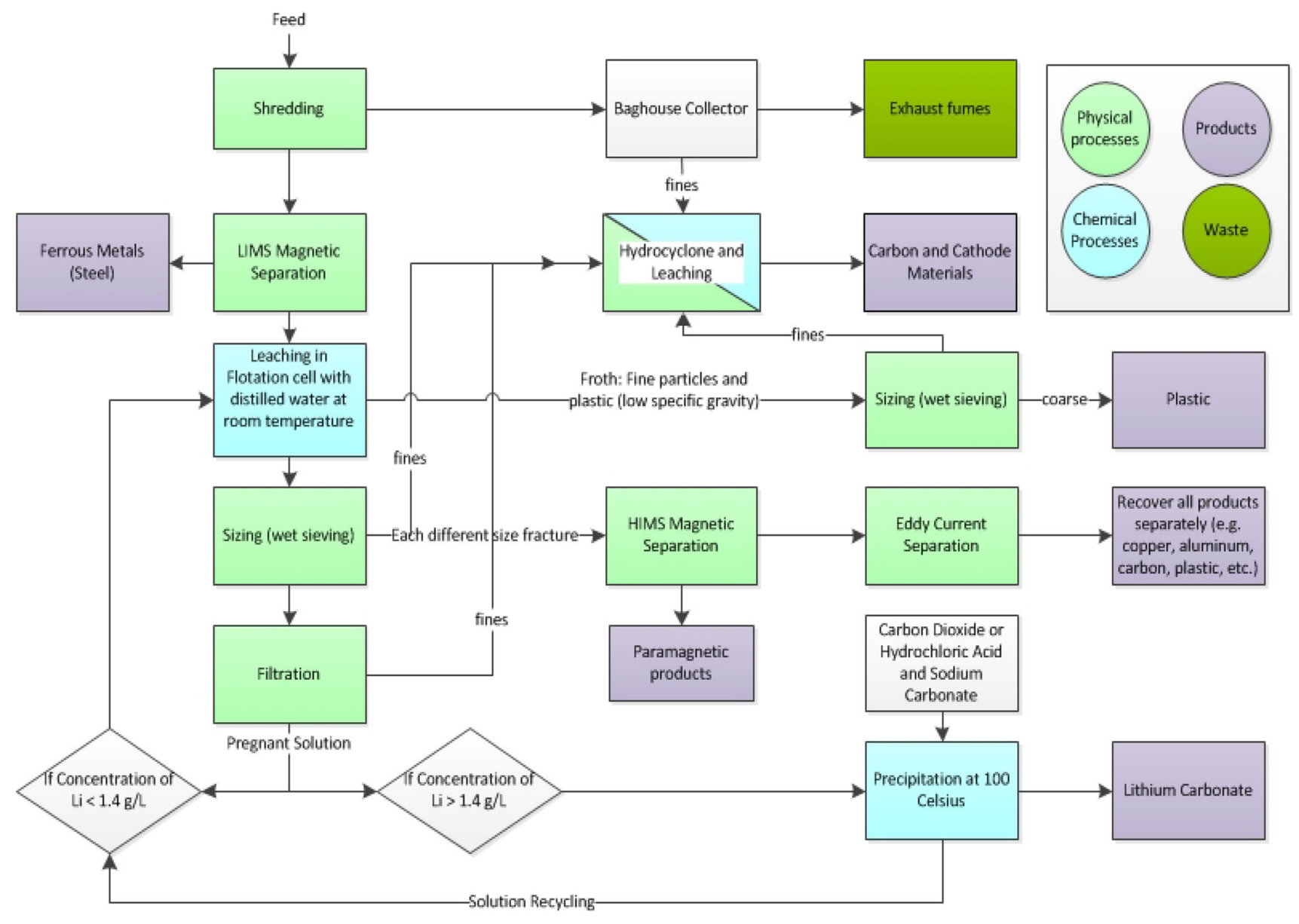

Fig. 1 Proposed flowsheet

\section{Low-Intensity Magnetic Separation}

The steel from the shredded batteries was removed using an Alnico hand magnet with a $25 \mathrm{lb}$. pull capacity.

\section{Optimized Leaching Conditions}

Leaching experiments were performed using temperature, time, solid/liquid pulp ratio, and stirring velocity as process variables. Since batteries have different amount of electrolyte $\left(\mathrm{LiPF}_{6}\right)$, the same package of batteries was used for each variable. Temperature was varied from room temperature to $50{ }^{\circ} \mathrm{C} .0 .5,1.0,1.5,2.0$, and $6.0 \mathrm{~h}$ were used as times for leaching. The solid to liquid ratios were maintained at 25, 35, and $50 \mathrm{~g} / \mathrm{L}$. For pulp densities over $35 \mathrm{~g} /$ $\mathrm{L}$, the mixture was slurry-like, and the velocity was kept below $215 \mathrm{rpm}$. All the leaching samples were tested using ICP-OES Standard Method.

\section{Leaching to Concentrate the Solution}

After the appropriate leaching conditions were optimized, the solution was concentrated by recycling it in subsequent leaching steps. An hour of leaching time at room temperature, $25 \mathrm{~g} / \mathrm{L}$ pulp-density, and $280 \mathrm{rpm}$ stirring velocity were used. The concentration leaching experiments were performed in a flotation machine that could effectively dissolve all the electrolytes and simultaneously float the plastics.

\section{Sizing (Wet Sieving)}

Sizing was performed in a sieving machine using three different sieves of 4,16 , and 50 mesh, respectively. The very fine material (less than 50 mesh) was not treated any further. The rest of the fractions were sent separately to a rare-earth roll magnetic separator and then to an eddycurrent machine.

\section{Jones Splitter}

After drying the material at ambient temperature, a Jones Splitter was used to get representative fractions of each different fraction $(+4,-4+16$, and $-16+50$ mesh). A sample from each fraction was used for ICP analysis, $25 \%$ 
Fig. 2 a Lithium concentration as a function of time and b Lithium recovery $(\%)$ as a function of time (h)
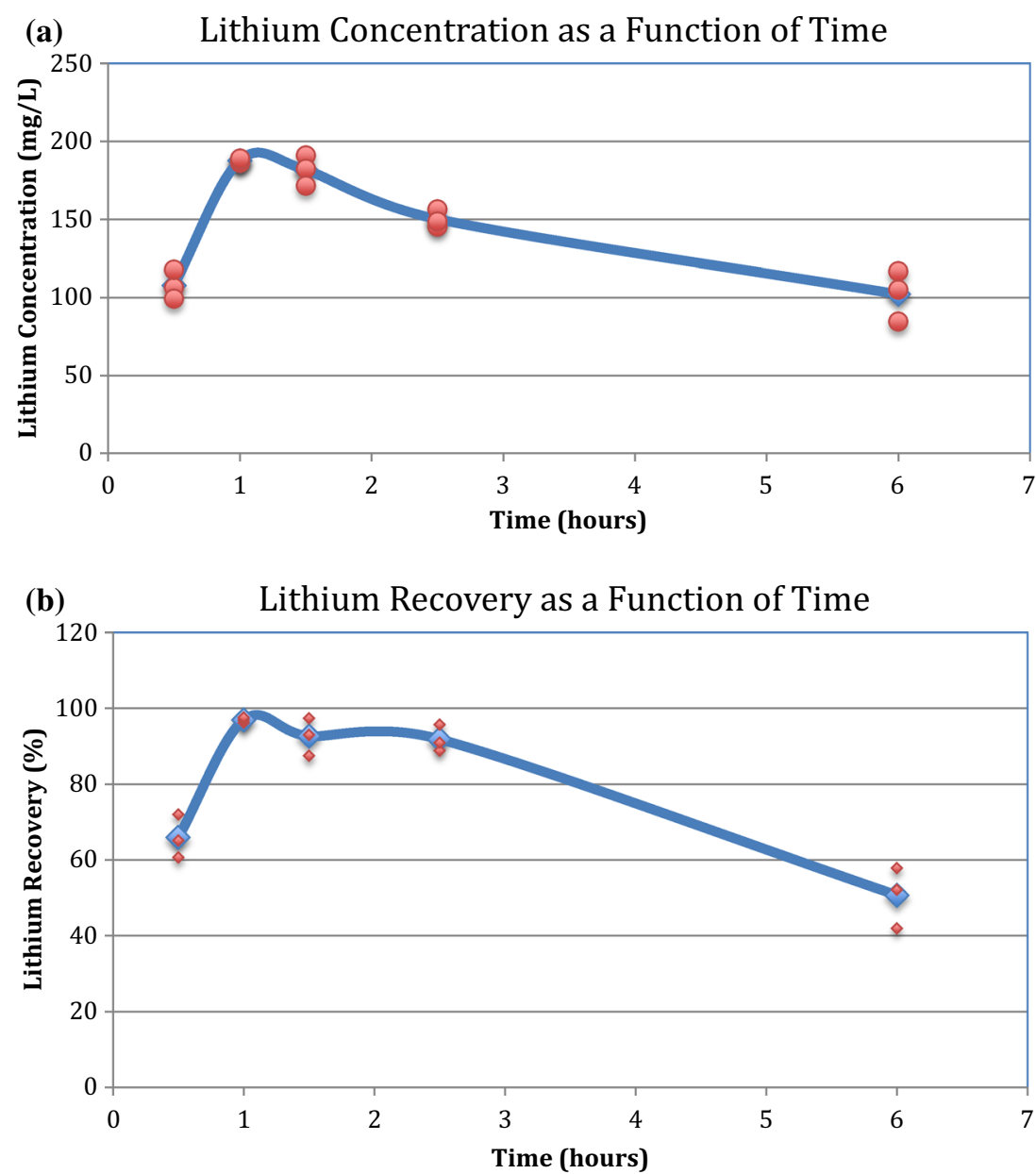

of the mass was sent to the rare-earth rolls, $25 \%$ to the eddy-current separator, and another $25 \%$ mass was sent to the rare-earth rolls and then to the eddy-current separator.

\section{Rare-Earth Roll Magnetic Separation and Eddy-Current Separation}

Each size fraction was processed to see if any further magnetic separation could be achieved. Half of the samples were sent to an REA Eddy-Current Separator from $-4+16$ mesh and the $-16+50$ mesh sizes for feasibility studies.

\section{Results and Discussion}

\section{Leaching Experiments}

\section{Time}

The time range for leaching included $0.5,1,1.5,2.5$, and $6 \mathrm{~h}$ using $50 \mathrm{~g}$ of battery per liter of distilled water, $280 \mathrm{rpm}$ stirring velocity, and room temperature. After the filtration, the solutions were analyzed using ICP-OES. The results are shown in Fig. 2a, where it can be seen that the highest lithium concentration is at $1-1.5 \mathrm{~h}$.

In Fig. 2b, the recovery of lithium is plotted assuming an $8 \% \mathrm{w} / \mathrm{w}$ of $\mathrm{LiPF}_{6}$ in the starting battery material. The long time $6 \mathrm{~h}$ experiment was performed because lithium recovery showed a small increase between 1.5 and $2.5 \mathrm{~h}$ but the $6 \mathrm{~h}$ experiments showed that the recovery decreases over time after $2.5 \mathrm{~h}$. The reason for the concentration of lithium to decrease is that as time passes, $\mathrm{CO}_{2}$ from the atmosphere gets through the solution, forming solid $\mathrm{Li}_{2} \mathrm{CO}_{3}$ and thus decreasing the amount of lithium dissolved in the solution.

\section{Temperature and Solid to Liquid Ratio}

The temperature conditions tested were room temperature and $50{ }^{\circ} \mathrm{C}$. Higher temperatures were not tested since $\mathrm{LiPF}_{6}$ has a low decomposition temperature. The solid/liquid ratios tested were 25,35 , and $55 \mathrm{~g} / \mathrm{L}$ for each temperature at $280 \mathrm{rpm}$ of stirring velocity and an hour of leaching. The results can be seen in Fig. 3a, where highest lithium concentration is achieved at room temperature and at a pulp 
Fig. 3 a Lithium recovery (\%) as a function of solid to liquid ratio $(\mathrm{g} / \mathrm{L})$ at room temperature and at $50{ }^{\circ} \mathrm{C}$ and $\mathbf{b}$ Lithium concentration $(\mathrm{mg} / \mathrm{L})$ as a function of solid/liquid ratio $(\mathrm{g} / \mathrm{L})$ at room temperature and at $50{ }^{\circ} \mathrm{C}$
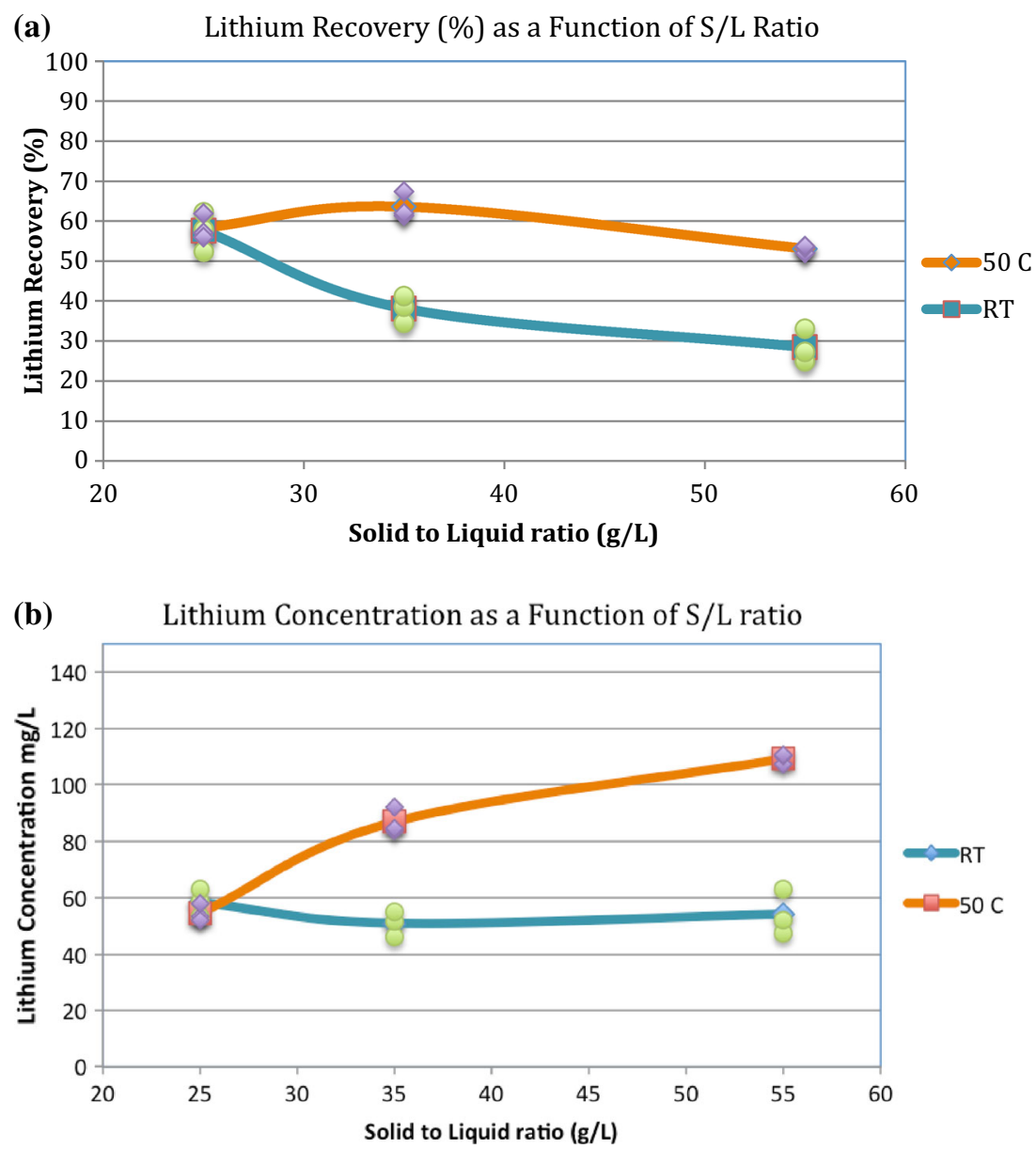

density of $25 \mathrm{~g} / \mathrm{L}$ decreasing gradually until it reaches $55 \mathrm{~g} /$ L. At $50{ }^{\circ} \mathrm{C}$, the concentration of lithium increases, showing the highest recovery at $55 \mathrm{~g} / \mathrm{L}$. The reaction is exothermic. However, the solubility depends on temperature and, in this case, as the temperature goes up, solubility increases. Solubility is also dependent on the stirring velocity. The stirring velocity was the same for all the experiments but for higher pulp densities, stirring rate could not be increased. Therefore, the recovery drops as the $\mathrm{S} / \mathrm{L}$ ratio increases.

Figure $3 \mathrm{~b}$ plots the recovery of lithium as a function of solid to liquid ratio at room temperature and at $50{ }^{\circ} \mathrm{C}$. At room temperature, the highest recovery of lithium can be observed at $25 \mathrm{~g} / \mathrm{L}$, again decreasing slowly until it reaches $55 \mathrm{~g} / \mathrm{L}$. At $50{ }^{\circ} \mathrm{C}$, the recovery of lithium increases, showing the highest point at $35 \mathrm{~g} / \mathrm{L}$.

\section{Stirring Velocity}

Stirring is difficult at high solid to liquid ratios. At $35-55 \mathrm{~g} / \mathrm{L}$, the stirring velocity could not go higher than $280 \mathrm{rpm}$. At $25 \mathrm{~g} / \mathrm{L}, 280 \mathrm{rpm}$ created a vortex, and thus, good transport was observed. Consequently, the optimized conditions that were chosen for the leaching are $1 \mathrm{~h}$ leaching time, room temperature, $25 \mathrm{~g} / \mathrm{L}$ solid to liquid ratio, and $280 \mathrm{rpm}$ stirring velocity.

\section{Leaching Materials of Varying Size Fractions}

The need for this work was established by sieving shredded battery through a 50 mesh sieve and leaching the two fractions separately. The percent of lithium recovered is calculated based on the total lithium recovered in milligrams (Fig. 4a). It is observed that most of the lithium is present in the coarse fraction. However, it should be noted that most of the cathode material is present in the fine fraction. Because the quantity of lithium recovered is already low in the range of 30-200 mg from one battery, the size fractions were not treated separately.

\section{Leaching Separate Battery Components}

A battery was hand-separated into plastic separator, the anode and the cathode, and leached separately. The solid to liquid ratio was analogous to the weight of each part. The 

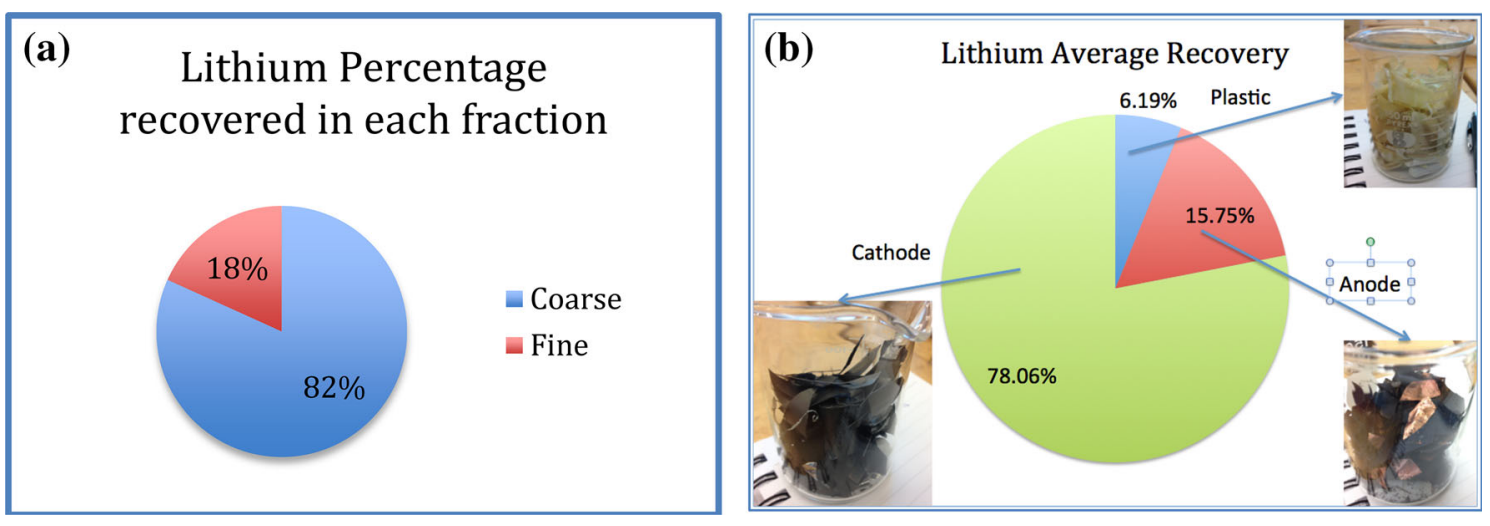

Fig. 4 a Lithium percentage recovered in each fraction (coarse \& fine) and b Lithium percentage recovered in each fraction (plastic, anode \& cathode)

(a)

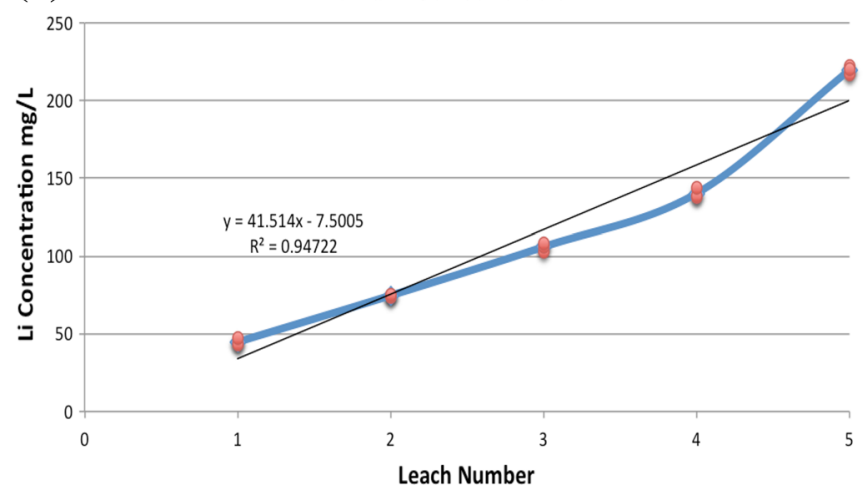

(b) Lithium Concentration

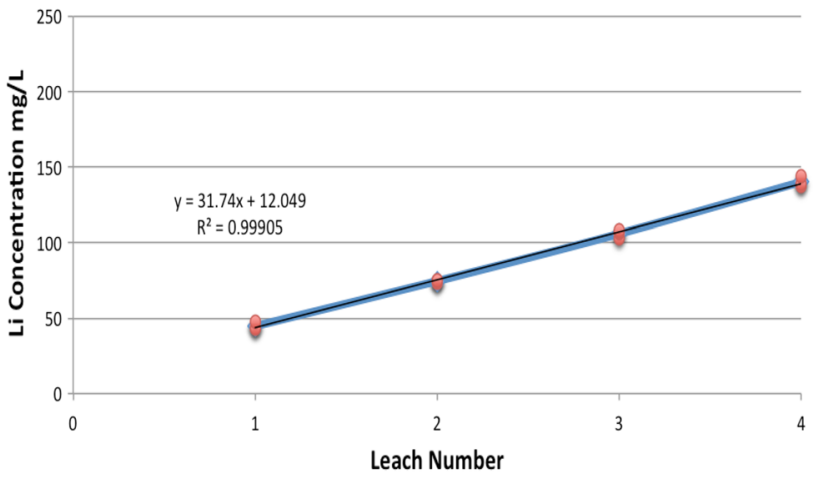

Fig. 5 a Lithium concentration as a function of the number of leaches, and $\mathbf{b}$ Lithium concentration as a function of the number of leaches, up to the fourth leach

theoretical weight of lithium in the starting material is calculated assuming $8 \% \mathrm{w} / \mathrm{w}$ of $\mathrm{LiPF}_{6}$. The percentage of lithium that was recovered in each fraction is shown in Fig. $4 \mathrm{~b}$ indicating that most of the lithium is present in the cathode part. Since, lithium is present in anode and the plastics as well, no components separation is justified. Plastics occupy large volume requiring higher material handling; it could be separated before leaching using heavy media separation, if economically justified.

\section{Leaching to Concentrate the Solution}

Electrolysis and evaporation, although viable options for lithium recovery from leached solution, were not considered due to high energy intensities. Industrially, lithium is usually precipitated from a lithium chloride solution using sodium carbonate as lithium carbonate. Lithium carbonate solubility decreases with temperature. Thus, at $100{ }^{\circ} \mathrm{C}$, lithium carbonate solubility is $7.2 \mathrm{~g} / \mathrm{L}$, and at room temperature, the solubility is $13.3 \mathrm{~g} / \mathrm{L}$. Consequently, to precipitate lithium carbonate at $100{ }^{\circ} \mathrm{C}$, the concentration of lithium has to be raised to at least up to $1.4 \mathrm{~g} / \mathrm{L}$. The concentration of lithium in all the experiments ranged from 30 to $200 \mathrm{mg} / \mathrm{L}$ or 0.03 to $0.2 \mathrm{~g} / \mathrm{L}$ from one battery at approx. $100 \%$ recovery.

The experiments conducted with multiple leaching with the recycled solution show that concentration increases with repeated use. The lithium recovery is calculated according to the cumulative theoretical amount of lithium contained in $\mathrm{LiPF}_{6}$, assuming $8 \% \mathrm{w} / \mathrm{w}$ in the battery. Figure 5a shows lithium concentration as a function of the number of leaches, and Fig. 5b shows lithium concentration up to the fourth leach using batteries from the same pack. It is seen that $\mathrm{R}$ is very close to one and would require leaching from 44 batteries to reach the threshold concentration of $1.4 \mathrm{~g} / \mathrm{L}$ of lithium in the solution.

Figure 6 shows that approx. $50 \%$ of the solids in solution are near the size of 2 microns and the other half is 


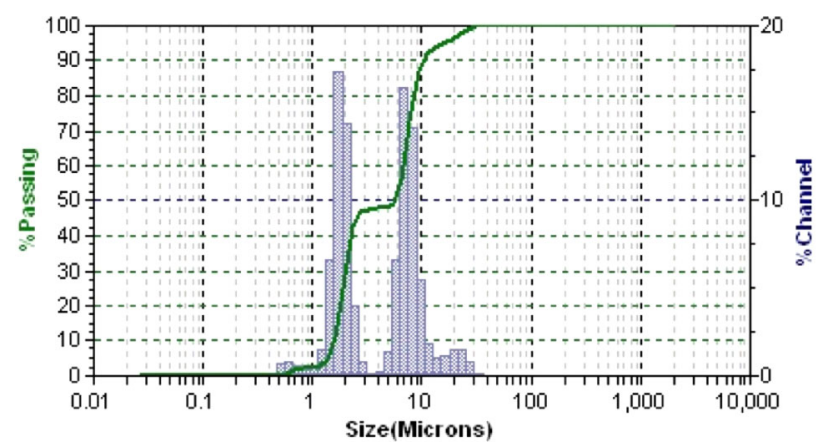

Fig. 6 Size distribution: percent passing compared to size in microns

approx. 8 microns. The use of a finer filter paper with an opening of 2.5 microns leaves half the particles in solution. Therefore, after every leach, more solids (less than $\sim 2.5 \mu \mathrm{m}$ ) were present in the solution. A solution to this problem can be the use of fiberglass filter which would allow the solution to be used for over forty times. It was confirmed that lithium could be precipitated either by adding hydrochloric acid to turn lithium hydroxide into lithium carbonate according to the reaction: $2 \mathrm{LiCl}+\mathrm{Na}_{2} \mathrm{CO}_{3} \rightarrow \mathrm{Li}_{2} \mathrm{CO}_{3}+2 \mathrm{NaCl}$, or by using $\mathrm{CO}_{2}$ to precipitate lithium carbonate from lithium hydroxide according to the reaction: $2 \mathrm{LiOH}+\mathrm{CO}_{2}=\mathrm{Li}_{2} \mathrm{CO}_{3}+$ $\mathrm{H}_{2} \mathrm{O}$. Precipitation was confirmed by preparing a solution with lithium concentration of $1.5 \mathrm{~g} / \mathrm{L}$.

\section{Mineral Processing}

\section{Flotation}

A pack of batteries was shredded where steel was not removed prior to leaching. Leaching was carried out in a floatation cell. After the leaching time passed, the air valve was opened to let the bubbles float the plastic. In Fig. 7a it can be seen that nothing floats while the air valve is closed, but plastic is separated when (Fig. 7b) air valve is opened.
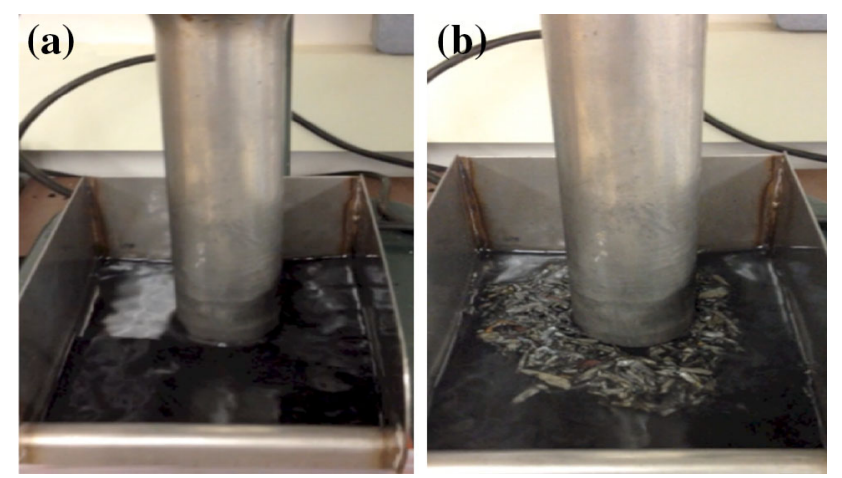

Fig. 7 Leaching in a flotation cell $\mathbf{a}$ air valve closed and $\mathbf{b}$ air valve opened

\section{Size Distribution}

The plastics - the overflow obtained from flotation-were separated, dried in ambient temperature, and weighed. The underflow was further processed and passed through multiple sieve nos. 4, 16, 50, 200, and 400. The +4 mesh material contained some copper, aluminum, the chips that are located inside the battery case but mostly steel. The +16 mesh material contained mostly aluminum, copper, and some wool that was present in the battery case. The +50 to -400 mesh materials were similar to each other containing mostly cathode powder, carbon, and some copper. The -400 mesh, the material that was filtered, also contained some metallic traces.

The size distribution can be seen in Fig. 8a. Around $20 \% \mathrm{w} / \mathrm{w}$ is the overflow, and thus, it may be concluded that leaching the material in a flotation cell is feasible and removes a lot of weight and volume to allow for less use of energy in further processing steps. The +4 mesh fraction accounts for $31 \%$ of the material but it mostly comprises steel. The percent retained, cumulative and passing were calculated according to the sieves. The size distribution can be seen in Fig. 8b. Since the fine materials were similar and would be difficult to recover through mineral processing, three sieve sizes, Nos. 4,16 , and 50 , were used.

(a)

\begin{tabular}{|c|c|c|c|c|c|}
\hline Sieve No & $\begin{array}{c}\text { Diameter } \\
(\mathrm{mm})=\end{array}$ & $\begin{array}{c}\text { Mass } \\
\text { Retained in } \\
\text { each sieve } \\
\text { (g) }\end{array}$ & $\begin{array}{c}\text { Mass } \\
\text { Percentage } \\
\text { in each } \\
\text { fractioi }\end{array}$ & $\begin{array}{c}\text { Percent } \\
\text { Retained } \\
(\%)\end{array}$ & $\begin{array}{c}\text { Cumulative } \\
\text { Retained } \\
\text { (\%) }\end{array}$ \\
\hline 4 & 4.75 & 15.54 & $31 \%$ & $54 \%$ & $54 \%$ \\
\hline 16 & 1.18 & 4.905 & $10 \%$ & $17 \%$ & $72 \%$ \\
\hline 50 & 0.3 & 0.711 & $1 \%$ & $2 \%$ & $74 \%$ \\
\hline 200 & 0.075 & 2.161 & $4 \%$ & $8 \%$ & $82 \%$ \\
\hline 400 & 0.038 & 0.708 & $1 \%$ & $2 \%$ & $84 \%$ \\
\hline Pan & & 4.497 & $9 \%$ & $16 \%$ & $100 \%$ \\
\hline SUM & & 28.522 & & $100 \%$ & \\
\hline Overflow & & 9.46 & $19 \%$ & & \\
\hline Impeller & & 10.486 & $21 \%$ & & \\
\hline Cleaning & & 2.012 & $4 \%$ & & \\
\hline Total SUM & & 50.48 & $100 \%$ & & \\
\hline
\end{tabular}

(b)

Size Distribution

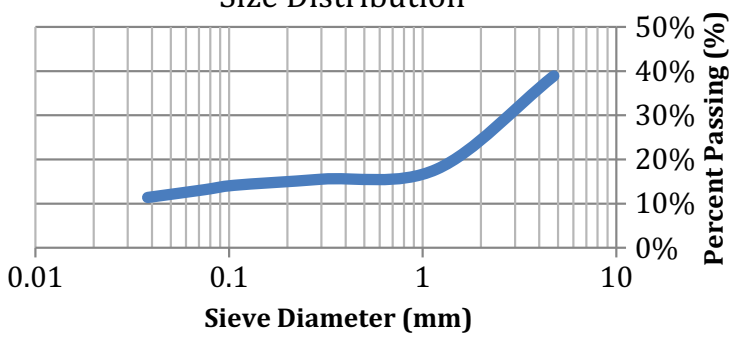

Fig. 8 a Size distribution table and b plotted size distribution of the sieved material 


\section{Magnetic Separation}

To avoid oxidation, steel should be removed prior to leaching. The shredded material was sieved through No. 200 sieve to check if all the steel was present in the coarse fraction. The fine material, -200 mesh, was looked at for steel content using a hand magnet. Some ferromagnetic material in the fine fraction was observed. Therefore, the process step sequence included shredding, magnetic separation using low-intensity magnet, and then leaching.

\section{Processing of a Larger Mass of Batteries}

In order to test the rare-earth high-intensity magnetic separation rolls and the eddy-current separation, all the settled leach residues were collected after plastics removal at a $25 \mathrm{~g} / \mathrm{L}$ solid to liquid ratio from four leach runs. The steel and the plastics that were removed can be seen in Fig. 9a, b. The -50 mesh materials were filtered out of solution and were not treated any further. They were analyzed using XRF to determine an indicative composition. The +4 mesh fraction can be seen in Fig. 9c. Some high specific gravity plastics, such as rings, did not float. Apart from these, the material is mostly composed of copper and aluminum. The $-4+16$ mesh fraction comprises mostly copper and aluminum (Fig. 9d). The $-16+50$ mesh fraction is seen in Fig. 9e comprising fine carbon and cathode powder with small amounts of copper and aluminum. These three fractions were further processed using a Jones Splitter. Fractions of these separate sizes were chemically analyzed
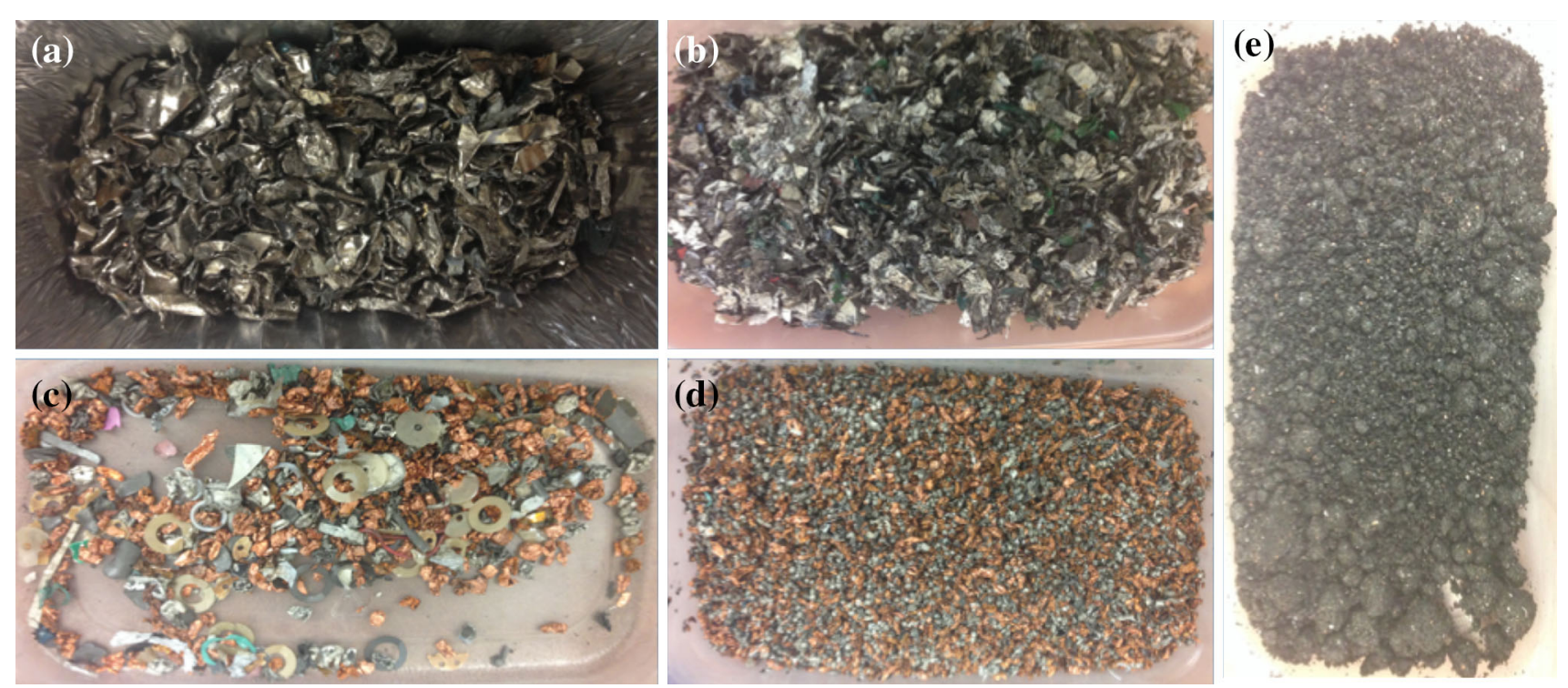

Fig. 9 a Steel removed before floating, b plastic, flotation overflow, $\mathbf{c}+4$ mesh fraction, $\mathbf{d}-4+16$ mesh fraction, and e $-16+50$ mesh fraction

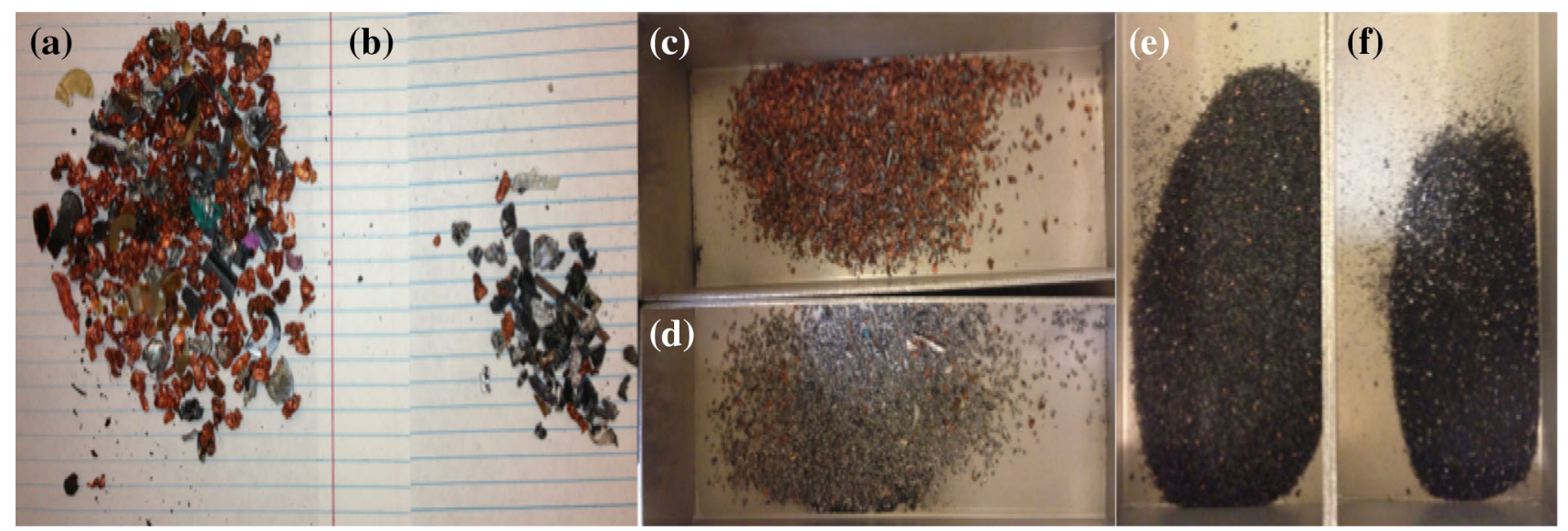

Fig. $10+4$ Mesh a non-magnetic fraction and $\mathbf{b}$ magnetic fraction, $4+16$ mesh $\mathbf{c}$ non-magnetic fraction and $\mathbf{d}$ magnetic fraction and $-16+50$ mesh e non-magnetic fraction and $\mathbf{f}$ magnetic fraction 

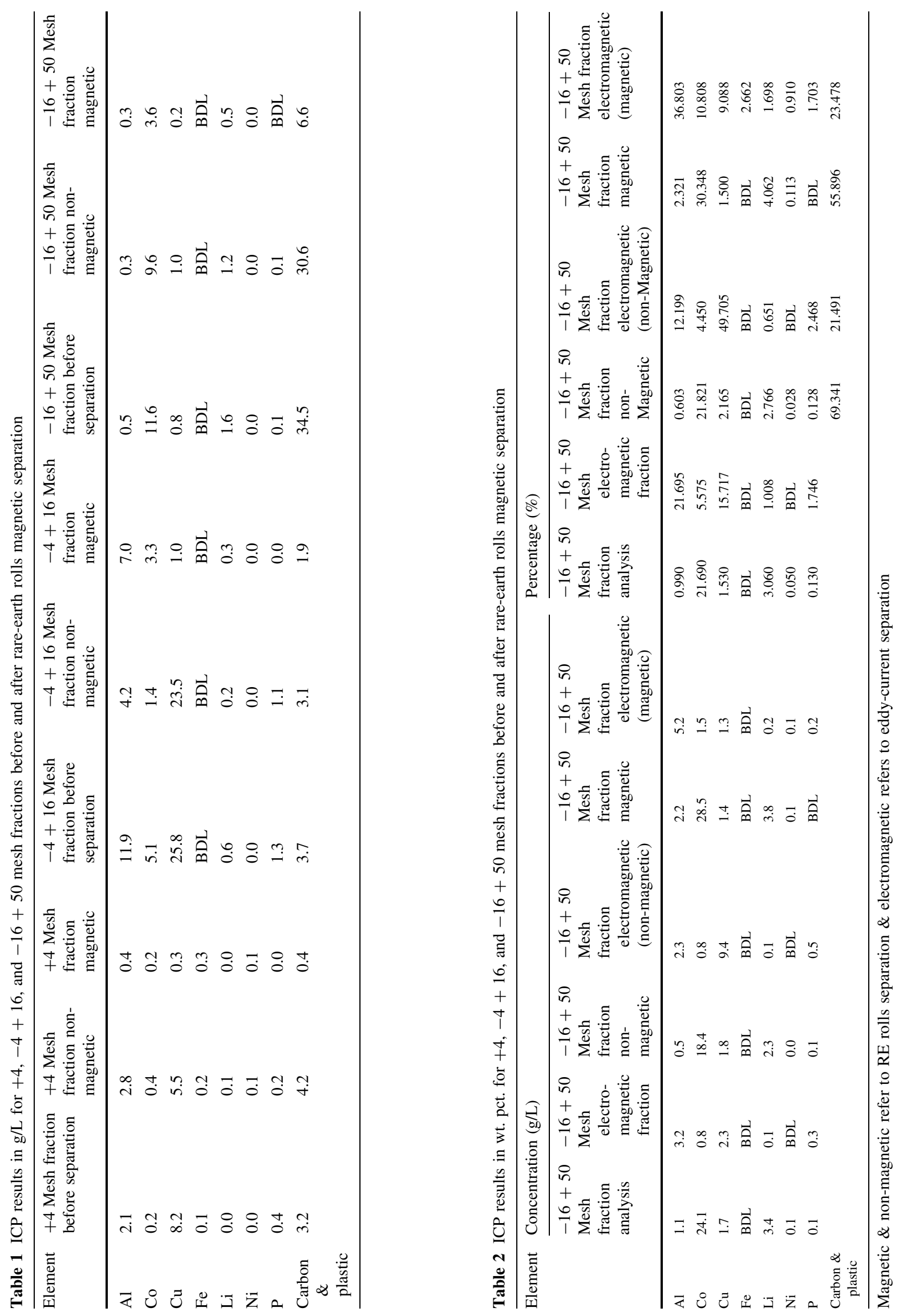


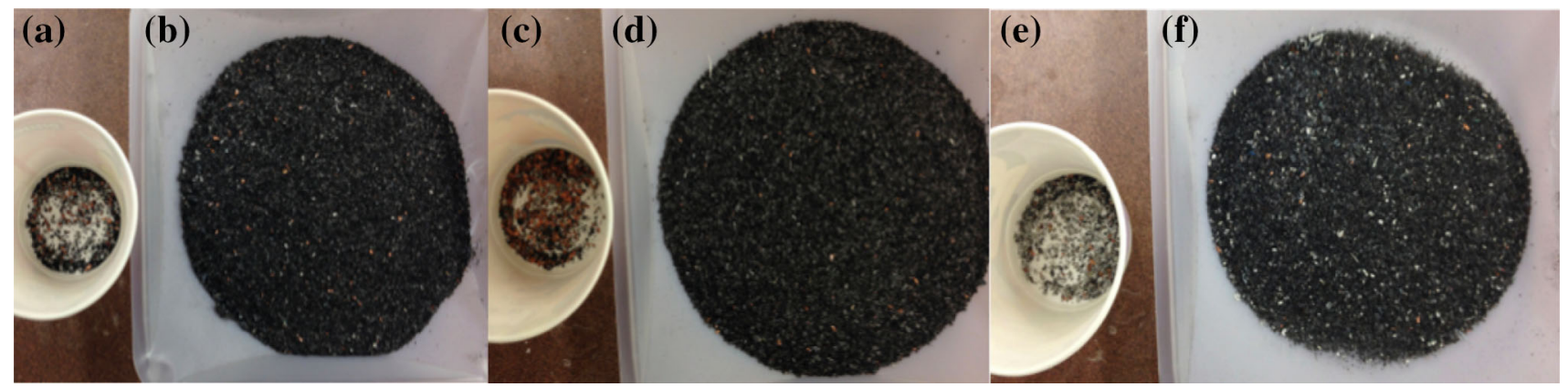

Fig. $11-16+50$ mesh fraction a electromagnetic fraction and b non-electromagnetic fraction, $\mathbf{c}$ electromagnetic non-magnetic fraction, $\mathbf{d}$ non- electromagnetic, non-magnetic fraction, e electromagnetic magnetic fraction, and $\mathbf{f}$ non-electromagnetic magnetic fraction

and further separated using high-intensity magnets and eddy current.

\section{Rare-Earth Rolls Separation}

For the $+4,-4+16$, and $-16+50$ mesh fractions, 100 , 50 , and $85 \mathrm{rpm}$ speeds, respectively, were used at a slow feed vibration. The non-magnetic and magnetic materials for each fraction can be seen in Fig. 10a, b. Both the magnetic and the non-magnetic fractions were dissolved in aqua regia and analyzed using ICP analysis. The results obtained from the ICP analysis can be seen in Table 1. In the +4 fraction, copper is a lot higher in the non-magnetic fraction. In Table 2, ICP results in weight percentage are shown, making it easier to compare the differences in concentration. The magnetic fraction is higher in aluminum content and shows some iron and nickel, which is probably some steel left over from magnetic separation using hand magnets. Although the separation is not fully favorable, a larger quantity of +4 mesh larger fraction would show better results.

Rare-earth rolls separation of $-4+16$ mesh fraction is shown in Fig. 10c and $\mathrm{d}$ for the non-magnetic and magnetic portions, respectively. Most of the aluminum is in the magnetic fraction as it is paramagnetic, while copper mostly reports to non-magnetic. The separated fractions were further sent for eddy-current separation. Both, the magnetic and the non-magnetic fractions, were analyzed using ICP, and the results are shown in Table 1 confirming that copper is a lot in the non-magnetic fraction, while aluminum is a lot higher in the magnetic. Also, most of the cobalt is gathered up in the magnetic fraction which is expected since it is a part of the cathode. In Table 2, ICP results are obtained in weight percentage for the $-4+16$ mesh fraction. It can be seen that aluminum was concentrated in the magnetic fraction from 23 to $50 \mathrm{wt} \%$, and copper was concentrated in the non-magnetic fraction from 50 to $66.7 \mathrm{wt} \%$. Also cobalt that usually follows aluminum was concentrated in the magnetic fraction from 10 to $23 \%$.
In this fraction, we see a very good separation that could be treated further.

Similar analysis for the $-16+50$ mesh fraction is shown in Fig. 10e, f for the non-magnetic and magnetic portions, respectively. These portions were also separated further using eddy current. The results obtained from ICP for this fraction are also included in Table 1, where it is further confirmed that in the magnetic fraction, aluminum and cobalt are higher. ICP results in Table 2, obtained for the $-16+50$ mesh fraction in wt. pct., show that aluminum was concentrated in the magnetic fraction from 0.603 to $2.321 \mathrm{wt} \%$ and copper was concentrated in the non-magnetic fraction from 1.526 to $2.165 \mathrm{wt} \%$. Also cobalt was concentrated in the magnetic fraction from 21.687 to $30.348 \%$. Carbon separation prior to these separations can further enhance the metal separation significantly.

\section{Eddy-Current Separation}

The $-16+50$ mesh fraction sample was held above the rotor contained in a larger clear bag and it was possible to "manually" effect a separation. For the $-4+16$ fraction samples, there was a great deal more agitation caused by the eddy-current rotor. Larger batch sample can be separated adequately by eddy current. It is concluded that since this fraction showed the best concentration after the rareearth rolls separation, treating with eddy current would occur in a much more concentrated material.

For the $-16+50$ fraction, Fig. 11a shows electromagnetic fraction and Fig. 11b shows non-electromagnetic fraction after eddy-current separation. The ICP results of the eddy-current separated material are shown in Table 3 as gram per liter that confirms the increase in aluminum and copper concentration and decrease in cobalt and lithium. In Table 3, ICP results are also shown in wt. pct. indicating that aluminum was concentrated in the electromagnetic fraction from 0.987 to $21.695 \mathrm{wt} \%$, and copper was concentrated from 1.526 to $15.717 \mathrm{wt} \%$. Also, cobalt decreased from 21.687 to $5.575 \mathrm{wt} \%$ and lithium from 


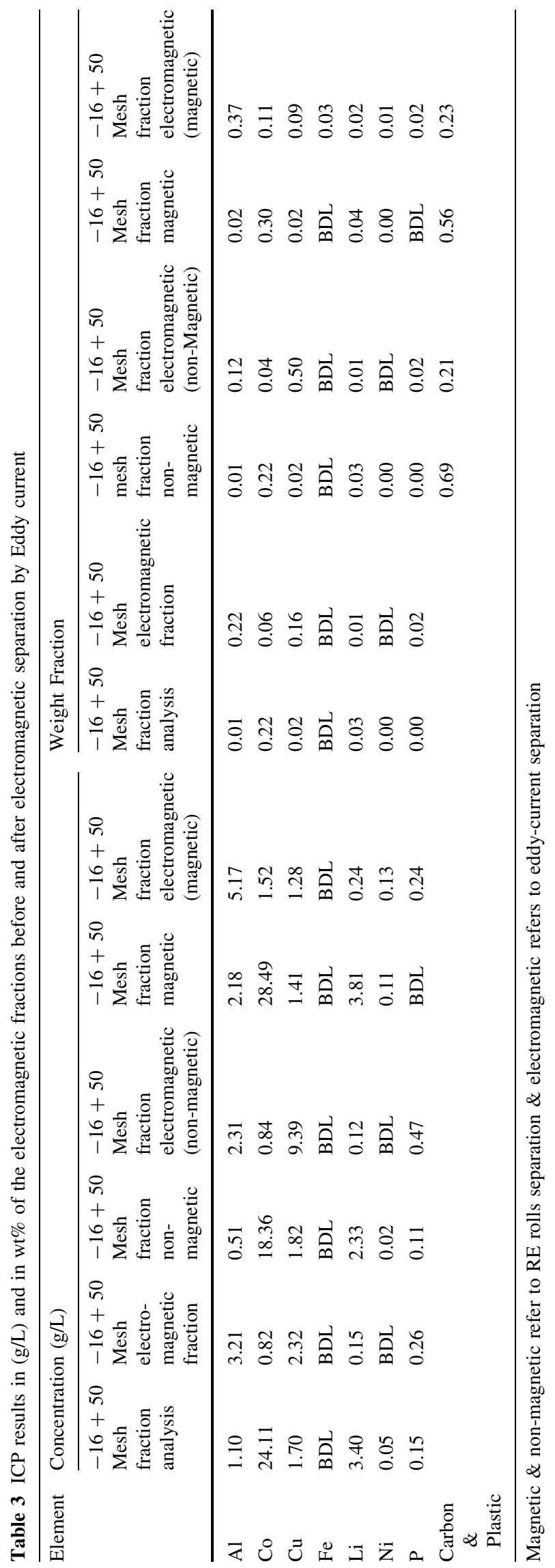

3.057 to $1.008 \mathrm{wt} \%$. However, almost half of the electromagnetic fraction was composed of carbon and plastics. If the experiment is run with a larger mass of sample and prior carbon and plastics removal through flotation, a much better concentration of metals can be expected.

In Fig. 11c-f, we can see the non-magnetic (RE rolls), electromagnetic fraction (Eddy current), the non-magnetic, non-electromagnetic fraction, the magnetic, electromagnetic fraction and the magnetic, non-electromagnetic fraction, respectively. The ICP results in concentration $(\mathrm{g} / \mathrm{L})$ can be seen in Table 3, where it is observed that, in both the magnetic and non-magnetic fractions, the aluminum concentration increases. Also, in both the magnetic and non-magnetic fractions, the cobalt and lithium concentrations decrease. The ICP results obtained for the $-16+50$ mesh fraction in weight percentage show that aluminum concentration increases from 0.603 to $12.199 \mathrm{wt} \%$ and copper from 2.165 to $49.705 \%$, while cobalt decreases from 21.821 to 4.450 $\mathrm{wt} \%$ and lithium decreases from 2.766 to $0.651 \mathrm{wt} \%$. For the magnetic fraction, it can be seen that aluminum was concentrated in the electromagnetic fraction from 2.321 to $36.803 \mathrm{wt} \%$ and copper was concentrated from 1.5 to 9.088 wt $\%$, while cobalt decreased from 30.348 to $10.808 \mathrm{wt} \%$ and lithium decreased from 4.062 to $1.698 \mathrm{wt} \%$ (Table 3). From the results, it may be concluded that processing the material through the rare-earth rolls first and then through the eddy current results in more concentrated products. Also, it can be observed that the rare-earth rolls provide a separation between the anode materials (copper) and the cathode materials (aluminum, cobalt, and lithium), while the eddy current seems to draw more copper and aluminum in the electromagnetic fraction and leave cobalt and lithium in the non- electromagnetic.

\section{Conclusions}

- It was shown that lithium contained in $\mathrm{LiPF}_{6}$ can be dissolved in distilled water and that the solution can be further concentrated.

- Leaching can be performed in a flotation cell to provide washing of the materials and plastic separation at the same time.

- Low-Intensity Magnetic Separation has to be done after the shredding, so that steel does not get oxidized during leaching.

- Rare-earth rolls separation proved to provide a separation between the anode (copper and carbon) and the cathode (aluminum and cathode powder), and Eddycurrent separation shows better results after the rareearth rolls separation than on the starting material.

- Eddy-current separation indicative test provided a superior separation between copper and aluminum in 
the electromagnetic fraction and cobalt and lithium in the non-electromagnetic fraction.

\section{References}

1. Fitzimmons M (2014) High power technology: easy $30 \%$ Upsid as lithium-ion battery demand to go parabolic. Seeking Alpha

2. http://en.wikipedia.org/wiki/Hybrid_electric_vehicles_in_the_Uni ted_States

3. Yazicioglu B, Tytgat J (2011) Life cycle assessments involving umicore's battery recycling process. DG Environment - Stakeholder Meeting, Umicore
4. Al-Thyabat S, Nakamura T, Shibata E, Lizuka A (2013) Adaptation of minerals processing operations for lithium-ion (LiBs) and nickel metal hydride (NiMH) batteries recycling: critical review. Miner Eng 45:4-17

5. Yazami R, Touzain J (1983) A reversible graphite-lithium negative electrode for electrochemical generators. J Power Source 9:365

6. Xu J, Thomas HR, Francis RW, Lum KR, Wang J, Liang B (2008) A review of processes and technologies for the recycling of lithium-ion secondary batteries. J Power Source 177(2):512-527

7. Zhang T, He Y, Wang F, Ge L, Zhu X, Li H (2014) Chemical and process mineralogical characterizations of spent lithium-ion batteries: an approach by multi-analytical techniques. Waste Manag 34(6):1051-1058 